\author{
Associate Professor Silvo DAJCMAN, PhD \\ E-mail: Silvo.dajcman@um.si \\ University of Maribor \\ Faculty of Economics and Business
}

\title{
A REGIONAL PANEL APPROACH TO TESTING THE VALIDITY OF OKUN'S LAW: THE CASE OF SLOVENIA
}

\begin{abstract}
This paper aims to study the validity of Okun's law for Slovenia at the national and regional level applying panel data. Different panel data and panel-time series model estimators are applied to test the sensitivity of results to the issues of heterogeneity, cross-section dependence, and endogeneity of regressors. We find that Okun's law is valid for Slovenia and 6 out of 12 of its regions. The results imply that all major issues listed in the time-series panel literature should be addressed when estimating Okun's coefficient with panel data.

Keywords: Okun's law, panel data, regional heterogeneity, cross-section dependence, endogeneity.
\end{abstract}

\section{JEL classification: E24, E32, C23}

\section{Introduction}

Marked by the Great Recession and the eurozone sovereign crisis, economic activity in Slovenia in 2009-2013 fell significantly, with negative effects on the labour market. ${ }^{1}$ The negative association between economic activity and unemployment is a well-established empirical regularity, known as Okun's law (Okun, 1962). The significance and strength of this association (i.e., Okun's coefficient) is important from an economic policy perspective. A significant and strong association implies that Keynesian-type economic policy stimulus may succeed in lowering the unemployment rate, while a non-significant or low association may indicate that unemployment is not cyclically driven and that measures that spur labour market flexibility are needed to bring unemployment down (Apergis and Rezitis, 2003; Binet and Facchini, 2013).

\footnotetext{
${ }^{1}$ According to data from the Statistical Office of Slovenia, gross domestic product (GDP) in 2013 was $9.57 \%$ lower than in 2008 in real terms, while the average annual registered rate of unemployment increased from $6.7 \%$ to $13.1 \%$. Not all statistical regions of Slovenia (there are 12, at the NUTS 3 (nomenclature of territorial units for statistics) level) were equally affected: Across the regions, the output (real GDP) fell from $2.1 \%$ to $11.4 \%$, while the rate of registered unemployment increased from 5.5 to 8.3 percentage points.
} 


\section{Silvo Dajcman}

The validity of Okun's law has been extensively analysed at the national level, applying mostly time series analysis, and the international level, applying either time series or panel data analysis (see, e.g., Balakrishnan et al., 2010; Ball et al., 2013). The foundational work of Freeman (2000) has recently invigorated the research on Okun's law at the regional level either to detect inter-regional differences in Okun's coefficient (e.g. Apergis and Rezitis, 2003;Oberst and Oelgemöller, 2013; Durech et al., 2014; Kuscevic, 2014; Guisinger et al., 2015) or to pool regional data to obtain country-level estimates of Okun's coefficients (e.g., Binet and Facchini, 2013; Oberst and Oelgemöller, 2013). ${ }^{2}$ The present paper joins the latter strand of literature with the aim of estimating the validity of Okun's law for Slovenia and each of its NUTS 3-level ${ }^{3}$ (nomenclature of territorial units for statistics) statistical regions. The latter, to our best knowledge, is not documented in the literature. The studies for Slovenia (Gabrisch and Buscher, 2006; Malačič et al., 2009; Cevik et al., 2014; Banerji et al., 2015) apply time series analysis, whereas our study is based on panel data. ${ }^{4}$

In the extant literature that uses panel data, only a handful of studies (e.g. Oberst and Oelgemöller, 2013) account for cross-section dependence, all by applying a spatial panel model specification. This approach only accounts for the issue of weak-form dependence, which arises due to physical proximity of crosssection units (regions), but not for a strong-form dependence which is due to variability in unobserved factors common to all cross-section units (regions) (see, e.g.,Chudik and Pesaran, 2013), including financial crises, economic policy measures, and regulation changes. The panel-time series literature (e.g., Pesaran, 2006, 2007; Chudik and Pesaran, 2013) notes that if the strong-form dependence is not accounted for, inconsistent parameter estimates may be obtained. A common approach in the panel-time series literature to account for this form of cross-section dependence is to use Pesaran's (2006) common correlated mean group (CCEMG) estimator. This approach, however, is not robust in the case of endogenous variables (see, e.g., Chudik and Pesaran, 2013; Neal, 2015) which may be the case when regressing the unemployment rate on the gross domestic product (GDP) growth.

\footnotetext{
${ }^{2}$ Freeman (2000) argues that the advantage of using regional data to assess Okun's coefficient is that not just the coefficients for specific regions are obtained, but also a greater variation of the dependent and explanatory variables in the econometric model when the cross section and time series are pooled, which allows for a more efficient estimation of Okun's coefficient at the national level.

${ }^{3}$ NUTSis the European classification of regions for statistical purposes. Slovenia is divided into 2 regions at the NUTS 2 level and 12 regions at the NUTS 3 level.

${ }^{4}$ The main challenges that need to be addressed within the panel econometric modelling framework include cross-section heterogeneity, cross-section dependence, and stationarity (see, e.g., Chudik and Pesaran, 2013).

${ }^{5}$ In this case, the GDP growth is "correlated with the error term beyond the presence of unobserved common factors" (Neal, 2015), which may lead to a biased parameter (Okun's
} 
A Regional Panel Approach to Testing the Validity of Okun'S Law: The Case of Slovenia

This paper uses regional data on the unemployment rate and output in Slovenia for 2000-2015 to estimate Okun's coefficient for Slovenia and each of its NUTS 3-level regions. The difference and gap models for calculation of Okun'scoefficient are estimated using estimators that allow for different levels of robustness to the main issues of time-series panel models: the fixed effects (FE) and mean group (MG) proposed by Pesaran and Smith (1995), the CCEMG proposed by Pesaran (2006), and the common correlated mean group two-stage least squares model specification (CCEMG-2SLS) proposed by Neal (2015). Applying the estimators allows us to evaluate the extent to which Okun's coefficient is affected by the panel time series issues of heterogeneity, crosssection dependence and endogeneity of regressors.

The paper is organized in five sections. After the introduction, a brief literature review is provided, followed by a description of the methodology applied. Presentation of data and the results follows in the fourth section, while the fifth section concludes the paper.

\section{Literature review}

In his foundational paper, Okun (1962) empirically derives a negative association between the actual growth of GDP and growth in the unemployment rate (the difference model) and between the cyclical GDP growth and cyclical unemployment (the gap model) known as Okun's law. By regressing the unemployment rate on the output growth data for the U.S. for 1947-1960, he obtains a parameter estimate (Okun's coefficient) of -0.3 , showing that a 1 percentage point increase in output is associated with a 0.3 percent point reduction in the unemployment rate.

The literature on Okun's law at the national is vast. One of the main findings of these papers is that Okun's coefficient may differ considerably from country to country ${ }^{6}$ and may change over time. ${ }^{7}$ The main factors behind country differences in (and time variability of) Okun's coefficients are related to structural differences (changes) in labour markets, such as flexibility and security of employment and unemployment benefits (Balakrishnan et al., 2010; Ball et al., 2013), different phases of economic cycles and economic shocks (Balakrishnan et

coefficient) estimate. To our best knowledge, no study simultaneously accounts for heterogeneity, cross-section dependence, and endogenous regressor(s) issues.

${ }^{6}$ Ball et al. (2013), calculating Okun's coefficient for 20 advanced economies for 19802011, find the coefficient to range between -0.136 (Austria) and -0.852 (Spain).

7 For instance, Balakrishnan et al. (2010), calculating Okun's coefficient from the difference model and applying the rolling-window approach, find that Okun's coefficient in 1990-2010 increases in absolute terms for Sweden (from approximately -0.1 to approximately -0.25 ) and the U.K. (from approximately -0.1 to just below -0.3 ), while it oscillates for the U.S. (between -0.2 and -0.3 ) and Germany (between -0.1 and just below 0.2). See also Durech et al. (2014) for a review of studies finding time and country heterogeneous Okun's coefficients. 


\section{Silvo Dajcman}

al., 2010), and differences and changes in labour market participation rates (see, e.g., Okun, 1962).

The literature on Okun's law at the regional level is relatively thin, including studies for U.S. regions (Freeman, 2000), states (Kuscevic, 2014; Guisinger, 2015), and metropolitan statistical areas (Kuscevic, 2014), regions of Greece (Apergis and Rezitis, 2003), the Czech Republic and Slovakia (Durech et al., 2014), France (Binet and Facchini, 2013), Germany (Oberst and Oelgemöller, 2013), and regions or provinces of Spain (Villaverde and Maza, 2009). Only a few studies find small diversity in Okun's coefficient (e.g., Freeman, 2000), while most find significant regional diversity in the size of Okun's coefficient. Some studies report that the coefficient is insignificant and therefore Okun's law does not apply for some regions in the country of investigation (e.g.Binet and Facchini, 2013; Durech et al., 2014). Other studies pool regional data to obtain country-level estimates of Okun's coefficients (e.g., Oberst and Oelgemöller, 2013). The issue of cross-sectional dependence between regions is recognized and accounted for only by a fraction of studies, mostly by applying the Durbin spatial model (Oberst and Oelgemöller, 2013; Kuscevic, 2014). Oberst and Oelgemöller (2013) note that a failure to account for spatial dependence results in over-estimation of Okun's coefficient.

Studies for Slovenia include Gabrisch and Buscher (2006), Malačič et al. (2009), Cevik et al. (2014), and Banerji et al. (2015). They all show that Okun's law for Slovenia is valid. Malačič et al. (2009) apply the gap model and, for quarterly time series data, obtain an Okun's coefficient of -0.31 . Gabrisch and Buscher (2006) study Okun's law for eight Central and Eastern European countries, including Slovenia, by applying the difference model. Okun's coefficient for Slovenia is estimated to be -0.20 for $1994:$ Q $-2004: Q 4$ and -0.16 for 1998:Q1-2004:Q4. Unlike Malačič et al. (2009), who use the ordinary least squares estimator (OLS), they estimate the model with a more robust two-stage least squares estimator. Cevik et al. (2014), applying the difference and the gap models, find that Okun's coefficient is cycle-dependent: During economic upswings, the coefficient is lower $(-0.042$ for the difference model and -0.076 for the gap model) than during economic downswings ( -0.093 for the difference model and -0.089 for the gap model). Banerji et al. (2015) investigate differences in Okun's coefficient for the youth and adult segments of the labour market for 22 advanced European countries, including Slovenia, covering 1980-2012. ${ }^{8}$ Okun's coefficient for the youth sector of Slovenia's labour market is -0.58 for the difference model and -0.4 for the gap model, while for the adult segment of the labour market it is -0.14 for the difference model and -0.19 for the gap model. As noted earlier, the extant literature does not document regional variation in Okun's coefficient for Slovenia.

\footnotetext{
${ }^{8}$ The exact period of investigation for Slovenia is not specified, but we assume that it covers 1990-2012.
} 
A Regional Panel Approach to Testing the Validity of Okun'S Law: The Case of Slovenia

\section{Methodology}

The difference model of Okun's law relates the change in unemployment rate to GDP growth. Written in the panel setting and formally taking account of heterogeneity and cross-section dependence between cross-section units, the model can be written as (confer Okun, 1962; Ball et al., 2013):

$\Delta U_{i t}=\alpha_{i}+\beta_{i} \Delta g d p_{i t}+\boldsymbol{\kappa}_{i}^{\prime} \boldsymbol{f}_{t}+\varepsilon_{i t}$,

where $U_{i t}$ is the unemployment rate, $\Delta$ is the first difference operator, $g d p_{i t}$ is a logarithm of real GDP, $i$ denotes a cross-section unit (region) $(i=1, \ldots N)$ and $t$ denotes time (year) $(t=1, \ldots T)$ of the panel, $\alpha_{i}$ is a constant for each cross section in the panel (fixed effects), and $\beta_{i}$ is the estimated slope coefficient (Okun's coefficient) assumed to be negative $\left(\beta_{i}<0\right)$. $\boldsymbol{f}_{t}$ is a $1 x z$ vector of common and unobserved factors that govern the cross-section dependence, $\boldsymbol{\kappa}_{i}$ is a $1 x z$ vector of regression coefficients for unobserved common factors, and $\varepsilon_{i t}$ is an idiosyncratic error term, which following the literature on panel-time series (e.g., Pesaran, 2006, 2007) may be spatio- and serially correlated but uncorrelated with $g d p_{i t}$. The inclusion of the fixed effects in the above specification, $\alpha_{i}$, assures that the effect of region-specific time-invariant factors on the regional unemployment, including, for example, regional differences in the industry structure, remoteness of regions, differences in the availability of housing and its costs, environmental factors, and demographic features, is captured. The common unobserved factors, $\boldsymbol{f}_{t}$, capture the effect of those unobserved time-varying variables that uniformly affect the unemployment rate across all cross-section units (regions), including financial crises, oil prices shocks, economic policy measures (monetary policy, fiscal policy, labour market policy, housing policy), and regulation changes, including labour market regulation. Model (1) thus captures the factors of unemployment commonly listed in the empirical models of unemployment and isolates the effect of output growth on changes in the unemployment rate. The common correlated mean group estimator, unlike the spatial econometrics approach applied in the extant studies, ensures that not only a weak-form crosssection dependence but also a strong cross-section dependence is correctly handled (see, e.g., Chudik and Pesaran, 2013).

Model (1) assumes that the potential GDP grows at a constant rate and that the natural rate of unemployment is constant (see, e.g., Okun, 1962; Ball et al., 2013). Releasing these rather restrictive assumptions, model (1) can be rewritten as a relationship between deviations in the actual unemployment rate from the natural rate of unemployment (i.e., cyclical unemployment) and deviations in the actual logarithm of real GDP from the logarithm of potential GDP (i.e., cyclical GDP growth) resulting in the gap model (confer, e.g., Ball et al., 2013): 


\section{Silvo Dajcman}

$U_{i t}-U_{i t}^{*}=\gamma_{i}+\lambda_{i}\left(g d p_{i t}-g d p_{i t}^{*}\right)+\boldsymbol{\mu}_{i}^{\prime} \boldsymbol{f}_{t}+u_{i t}$,

where $U_{i t}$ is the actual unemployment rate, $U_{i t}^{*}$ is the natural rate of unemployment, $g d p_{i t}$ is a logarithm of real GDP, $g d p_{i t}^{*}$ is a logarithm of potential GDP, $i$ denotes a cross-section unit (region) of the panel, $t$ denotes time (year), $\gamma_{i}$ is a constant for each cross section in the panel (fixed effects), $\lambda_{i}$ is a slope coefficient (Okun's coefficient) assumed to be negative, and $u_{i t}$ is an idiosyncratic error term. $\boldsymbol{f}_{t}$ is a $1 x z$ vector of common and unobserved factors that govern the cross-section dependence (we assume the same set of common unobserved factors as in the first model), $\boldsymbol{\mu}_{i}$ is a $1 x z$ vector of regression coefficients for unobserved common factors, and $\varepsilon_{i t}$ denotes errors, with the same characteristics as in model (1).

Models (1) and (2) nest several possible panel data model specifications. The most parsimonious model specification, which imposes a uniform response of unemployment rate to GDP growth across regions (i.e., does not allow for heterogeneity of Okun's coefficients, $\beta$ and $\lambda$, respectively) and does not control for the cross-section dependence across the panel groups (regions), is the fixed effects (FE) model:

$\Delta U_{i t}=\alpha_{i, F E}+\beta \Delta g d p_{i t}+\varepsilon_{i t, F E}$

$U_{i t}-U_{i t}^{*}=\gamma_{i, F E}+\lambda\left(g d p_{i t}-g d p_{i t}^{*}\right)+u_{i t, F E}$

Allowing for heterogeneity of Okun's slope coefficients, but not controlling for the cross-section dependence across the panel groups (regions) yields the mean group (MG) model of Pesaran and Smith (1995):

$\Delta U_{i t}=\alpha_{i, M G}+\beta_{i, M G} \Delta g d p_{i t}+\varepsilon_{i t, M G}$

$U_{i t}-U_{i t}^{*}=\gamma_{i, M G}+\lambda_{i, M G}\left(g d p_{i t}-g d p_{i t}^{*}\right)+u_{i t, M G}$,

where $\beta_{i, M G}$ and $\lambda_{i, M G}$ are Okun's coefficients for individual regions, obtained by estimating the model for each region in the panel using OLS. A consistent countrylevel estimate of Okun's coefficient is obtained by calculating the mean Okun's coefficient for the regions ${ }^{9}$ (see Pesaran and Smith (1995) for a detailed description).

Both issues (i.e., heterogeneity of Okun's slope coefficients and crosssection dependence generated by (unobserved) common factors) can be addressed

\footnotetext{
${ }^{9}$ See Pesaran and Smith (1995) for the proof of consistency of the parameter estimates obtained by the MG estimator.
} 
A Regional Panel Approach to Testing the Validity of Okun'S Law: The Case of Slovenia

by applying the common correlated effects mean group model (CCEMG) specifications of (1) and (2): ${ }^{10}$

$\Delta U_{i t}=\alpha_{i, C C E M G}+\beta_{i, C C E M G} \Delta g d p_{i t}+\kappa_{0 i, C C E M G} \overline{\Delta U}_{i t}+\kappa_{1 i, C C E M G} \overline{\Delta g d p}_{i t}+\varepsilon_{i t, C C E M G}(1 \mathrm{c})$

$U_{i t}-U_{i t}^{*}=\gamma_{i, C C E M G}+\lambda_{i, C C E M G}\left(g d p_{i t}-g d p_{i t}^{*}\right)+$

$+\mu_{0 i, C C E M G}\left(\overline{U_{l t}-U_{l t}^{*}}\right)+\mu_{1 i, C C E M G}\left(\overline{g d p_{l t}-g d p_{l t}^{*}}\right)+u_{i t, C C E M G}$,

where. denotes the average of the variables across the regions and $\beta_{i, C C E M G}$ and $\lambda_{i, C C E M G}$ are Okun's coefficient estimates obtained by estimating the model for each region in the panel using the OLS estimator. A consistent country-level Okun's coefficient estimate is obtained from regional Okun's coefficients the same way as in the MG model: by taking the average of Okun's coefficient estimates for the individual regions. ${ }^{11}$

To control for heterogeneity of Okun's slope coefficients, the cross-section dependence, and endogeneity of regressors, following Neal (2015), the individual Okun's coefficient estimates are obtained by estimating models (1c) and (2c) for each region in the panel using the two-stage least squares (2SLS) estimator. Consistent country-level Okun's coefficient estimates are obtained from regional Okun's coefficients by taking the average of the Okun's coefficient estimates for individual regions. Going forward, we refer to this model specification as the CCEMG-2SLS.

All models are estimated using Stata: the FE model specification with the in-build codes, the MG and the CCEMG with the xtmg code of Eberhardt (2012), and the CCEMG-2SLS model specification with the xtcce code of Neal (2016).

\section{Data and the empirical results}

All empirical models are estimated including all Slovenian regions: Pomurska, Podravska, Koroška, Savinjska, Zasavska, Spodnjeposavska, JugovzhodnaSlovenija, Osrednjeslovenska, Gorenjska, Notranjsko-kraška, Goriška, and Obalno-kraška. Data consist of yearly observations for 2000-2015, limited by data availability. The panel sample is balanced. Specifications of the variables used in the models are presented in Table 1.

\footnotetext{
${ }^{10}$ As shown byPesaran (2006) the common factors in thecommon correlated effects mean group estimatorneed not be explicitly determined because they can be accounted for by the cross-section averages of the model's observed variables.

${ }^{11}$ See Pesaran (2006) for the proof of consistency of the parameter estimates obtained by the CCEMG estimator.
} 
Table 1: Specification of variables used in the empirical models

\begin{tabular}{|c|c|c|}
\hline Variable & Description & Source \\
\hline $\begin{array}{l}\text { Unemployment } \\
\text { rate }\left(U_{i t}\right) \text { in the } \\
\text { region } i \text { and year } t\end{array}$ & $\begin{array}{l}\text { Average yearly rate of registered } \\
\text { unemployment, as defined by the } \\
\text { Employment Service of Slovenia }\end{array}$ & $\begin{array}{l}\text { Employment } \\
\text { Service of } \\
\text { Slovenia }\end{array}$ \\
\hline $\begin{array}{l}\text { Natural logarithm } \\
\text { of the real GDP } \\
\left(g d p_{i t}\right) \text { for the } \\
\text { region } i \text { and year } t\end{array}$ & $\begin{array}{l}\text { Real annual GDP; real value is obtained } \\
\text { by deflating nominal GDP by the } \\
\text { Harmonized Index of Consumer Prices } \\
\text { (HICP) }\end{array}$ & $\begin{array}{l}\text { Republic of } \\
\text { Slovenia } \\
\text { Statistical } \\
\text { Office }\end{array}$ \\
\hline $\begin{array}{l}\text { Natural rate of } \\
\text { unemployment } \\
\left(U_{i t}^{*}\right) \text { in the region } i \\
\text { and year } t\end{array}$ & $\begin{array}{l}\text { The natural rate of unemployment is } \\
\text { proxied by the trend unemployment rate } \\
\text { by applying the Hodrick-Prescott } \\
\text { filter }{ }^{12} \text {; the smoothing parameter, as } \\
\text { common in the literature, is set to } 6.25\end{array}$ & $\begin{array}{l}\text { Own } \\
\text { calculations } \\
\text { based on the } \\
\text { primary data } \\
\text { for } U_{i t}\end{array}$ \\
\hline $\begin{array}{l}\text { Natural logarithm } \\
\text { of the potential } \\
\text { GDP }\left(g d p_{i t}^{*}\right) \text { for } \\
\text { the region } i \text { and } \\
\text { year } t\end{array}$ & $\begin{array}{l}\text { The potential GDP is proxied by the } \\
\text { trend GDP by applying the Hodrick- } \\
\text { Prescott filter; the smoothing } \\
\text { parameter, as common in the literature, } \\
\text { is set to } 6.25\end{array}$ & $\begin{array}{l}\text { Own } \\
\text { calculations } \\
\text { based on the } \\
\text { primary data } \\
\text { for } g d p_{i t}\end{array}$ \\
\hline
\end{tabular}

Figure 1 depicts the regional diversity in growth of real GDP and the unemployment rate during the observed time period. A contraction in output in2009-2013 accompanied by a surge in the unemployment rate is evident for all regions.

\footnotetext{
${ }^{12}$ While alternative methods can be used to estimate the potential GDP and the natural rate of unemployment, the Hodrick-Prescott filter is likely the most frequently applied statistical method to estimate the potential GDP and the natural rate of unemployment. This is one argument for use of this method, the other is its ease of use.
} 
A Regional Panel Approach to Testing the Validity of Okun'S Law: The Case of Slovenia

Figure 1: Growth of real GDP and unemployment rate across the regions of Slovenia

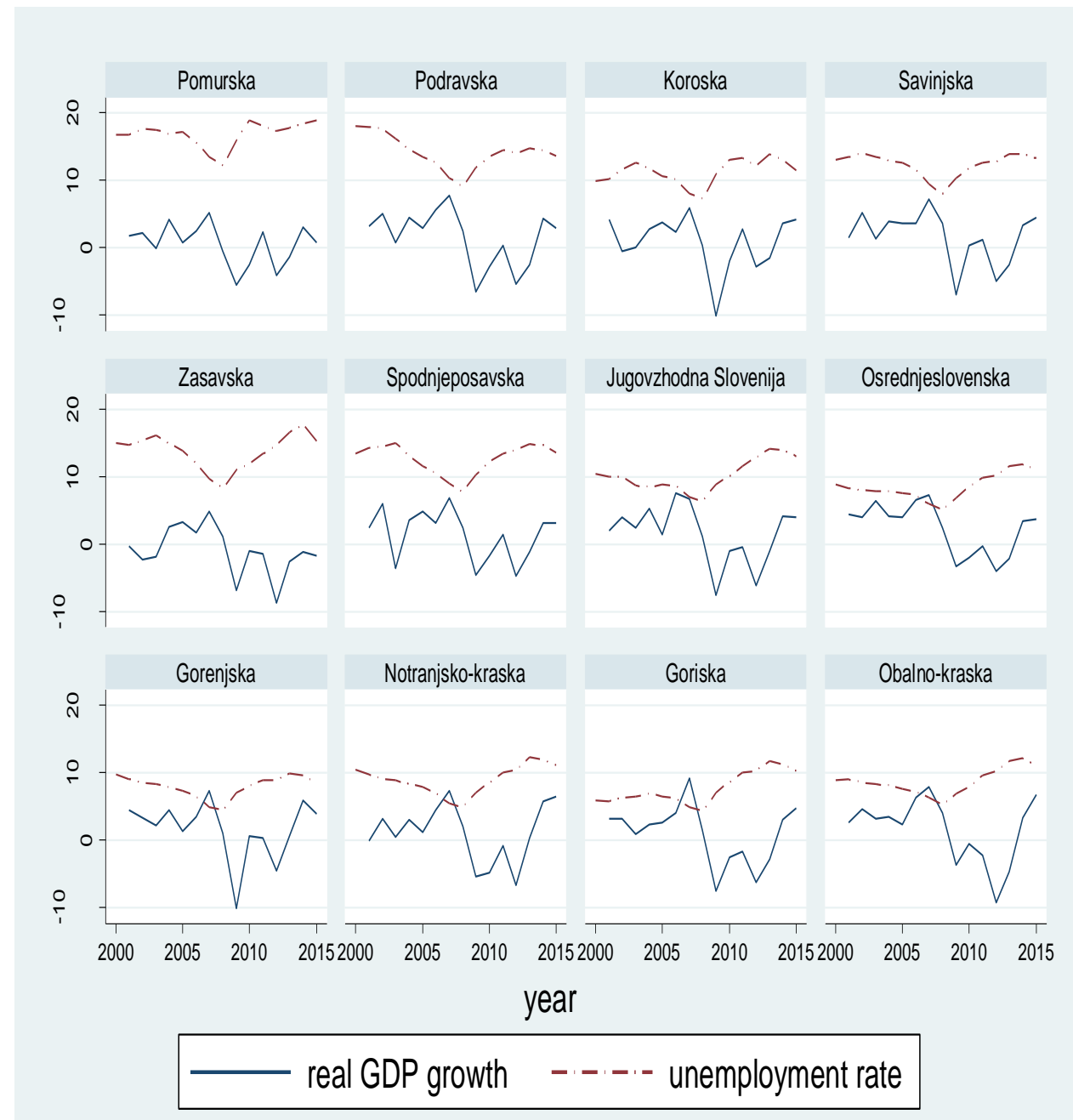

Notes: Real GDP growth is a first difference of $g d p_{i t}$; $\mathrm{U}$ (unemployment rate) is the registered unemployment rate.

Source: Data from Statistical Office of Slovenia and own calculations.

Pesaran's (2004) cross-section dependence (CD) test is applied to test for cross-section dependence between the cross-section units (regions) in the raw panel data. The results, presented in Table 2, indicate that the cross-section dependence is an issue for the variables considered in the panel and must be addressed in the econometric estimation of models (1a)-(1c) and (2a)-2(c). Given the time 


\section{Silvo Dajcman}

dimension of the panel data sample (covering 16 time periods), the nonstationarity and cointegration between the unit root variables may cause a spurious regression issue. The CIPS unit root test of Pesaran (2007), robust to cross-section dependence, shows (Table 2) that the dependent and explanatory variables used in the empirical models are stationary. Spurious regression is thus not an issue in our case.

Table 2: Results of the cross-section dependence (CD) test and the CIPS test

\begin{tabular}{|c|c|c|c|c|}
\hline \multirow{2}{*}{$\begin{array}{l}\text { Variable of models } \\
(1 \mathrm{a})-(1 \mathrm{c}) \text { and (2a)- }\end{array}$} & $\begin{array}{c}\text { Cross section } \\
\text { dependence test } \\
\text { results* }\end{array}$ & \multicolumn{3}{|c|}{ CIPS test results** } \\
\cline { 3 - 5 } & 25.91 & No. of lags 1 & No. of lags 2 & No. of lags 3 \\
\hline$\Delta U_{i t}$ & $(0.000)$ & -2.782 & -2.742 & -2.618 \\
\hline \multirow{2}{*}{$\Delta g d p_{i t}$} & 26.57 & -2.834 & -2.408 & $(0.001)$ \\
\hline \multirow{2}{*}{$U_{i t}-U_{i t}^{*}$} & $(0.000)$ & $(0.000)$ & $(0.016)$ & -2.767 \\
& 27.36 & -3.414 & -2.936 & $-2.400)$ \\
\hline$g d p_{i t}-g d p_{i t}^{*}$ & $(0.000)$ & $(0.000)$ & $(0.000)$ & $(0.008)$ \\
& 28.11 & -3.460 & -2.799 & -2.714 \\
& $(0.000)$ & $(0.000)$ & $(0.000)$ & $(0.001)$ \\
\hline
\end{tabular}

Notes: *The table presents the statistics of the CD test and the significance level (in brackets) for rejection of the null hypothesis of no dependence between cross-section units. For details of the test, see Pesaran (2004). Eberhardt's (2017) xtcd Stata code was used for the test. **The table reports the standardized CIPS statistics. The significance levels for rejection of the null hypothesis of the unit root for all regions in the panel are reported in brackets. Different lag specifications of the test are allowed to control for a serial correlation. In the CIPS test, only a constant is used because no visible trend is observed in the variables. See Pesaran (2007) for details of the CIPS unit root test. For the CIPS test, the Stata code pescadf of Lewandowski (2007) is applied.

The parameter estimates along with diagnostics tests of models (1a)-(1c) are presented in Table 3 while for models (2a)-2(c) in Table 4. The results show that the FE and MG model specification estimates of the country-level Okun's coefficient are similar to each other and somewhat higher than the estimates from the CCEMG and CCEMG-2SLS model specifications, which also are close to each other. Two main statistical diagnostic tests are performed to help judge the statistical merits of the models. The goodness of fit (measured by the root mean square error, RMSE) improves with the models that take account of cross-section dependence (CCEMG and CCEMG-2SLS). A CD test is performed to measure the extent to which the cross-section dependence in the residuals of the estimated models is an issue (to recall, inconsistent parameter estimates may result). Evidently, for the FE and MG models, the cross section is an issue, as indicated by rejection of the null hypothesis of no cross-section dependence by the CD test. The CCEMG and CCEMG-2SLS model specifications considerably reduce the problem of cross-section dependence, in both the difference and the gap model; the null of no cross-section dependence in the errors cannot be rejected at the typical significance levels for rejection of the null hypothesis. In the difference model, the CCEM-2SLS performs best in reducing the cross-section dependence problem, while in the gap model this is achieved using the CCEMG model. The results of the diagnostic tests show that the cross-section dependence and heterogeneity of 
A Regional Panel Approach to Testing the Validity of Okun'S Law: The Case of Slovenia

Okun's coefficient must be addressed in panel data studies on the validity of Okun's coefficient.

According to Neal (2015), the CCEMG-2SLS model, unlike the CCEMG model, is robust to endogeneity in regressors. This, coupled with the diagnostic tests, singles out the CCEMG-2SLS model specification as preferred from a statistical point of view.

Table 3: Results of the regression models (1a)-(1d) and: country-level estimates

\begin{tabular}{|c|c|c|c|c|}
\hline \multirow{2}{*}{$\begin{array}{l}\text { Explanatory } \\
\text { variable }\end{array}$} & \multicolumn{4}{|c|}{ The difference model } \\
\hline & $\begin{array}{l}\mathrm{FE} \\
\text { (1a) }\end{array}$ & $\begin{array}{l}\text { MG } \\
(1 \mathrm{~b})\end{array}$ & $\begin{array}{l}\text { CCEMG } \\
(1 \mathrm{c})^{\mathrm{A}}\end{array}$ & $\begin{array}{c}\text { CCEMG- } \\
\text { 2SLS } \\
(1 \mathrm{c})^{\mathrm{A}, \mathrm{B}}\end{array}$ \\
\hline Constant & $\begin{array}{r}.0033 * * * \\
(.0167)\end{array}$ & $\begin{array}{r}.0031 * * * \\
(.0007)\end{array}$ & $\begin{array}{r}-.0004 \\
(.0006)\end{array}$ & $\begin{array}{r}-.0004 \\
(.0007)\end{array}$ \\
\hline$\Delta g d p_{i t}$ & $\begin{array}{r}-.2336 * * * \\
(.0007) \\
\end{array}$ & $\begin{array}{r}-.2431 * * * \\
(.0167)\end{array}$ & $\begin{array}{r}-.1468 * * * \\
(.0520)\end{array}$ & $\begin{array}{r}-.1628 * * \\
(.0672)\end{array}$ \\
\hline$g d p_{i t}-g d p_{i t}^{*}$ & I & / & I & I \\
\hline \multicolumn{5}{|c|}{ Statistical features of the estimated models: } \\
\hline$R^{2}$ (within) & .5407 & / & l & I \\
\hline $\mathrm{RMSE}^{\mathrm{C}}$ & .0087 & .0081 & .0042 & .0044 \\
\hline CD test ${ }^{\mathrm{D}}$ & $\begin{array}{l}26.57 \\
(.000) \\
\end{array}$ & $\begin{array}{l}19.88 \\
(.000)\end{array}$ & $\begin{array}{r}-1.65 \\
(.100) \\
\end{array}$ & $\begin{array}{r}-1.49 \\
(.135) \\
\end{array}$ \\
\hline
\end{tabular}

Notes: The results of models (1a)-(1c) are presented. Although the models written above do not contain a constant, Stata reports the constant as the average of fixed effects. This does not affect parameter estimates. The standard errors of parameter estimates are given under the parameter estimates. $* * * / * * / *$ denote the $1 \% / 5 \% / 10 \%$

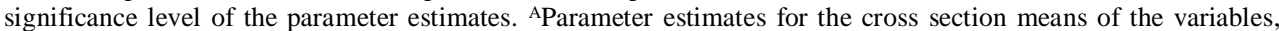
specified in models (1c), are not reported because they have no reasonable economic interpretation. ${ }^{\mathrm{B}}$ Following Neal (2015), the instrumental variable approach to 2SLS is applied. The cross-section averages, a constant and the first and second lag of the regressor and the dependent variable, are used as instruments in the CCEMG-2SLS model. For details, see Neal (2015). ${ }^{C}$ RMSE is the root mean square error. DD test is the Pesaran's (2004) crosssection dependence test. The test statistics and the significance level for rejection of the null are noted (in parentheses). The Stata code xtcd of Eberhardt (2017) is used for the CD test. 
Table 4: Results of the regression models (2a)-2(d): country-level estimates

\begin{tabular}{|c|c|c|c|c|}
\hline \multirow{2}{*}{$\begin{array}{l}\text { Explanatory } \\
\text { variable }\end{array}$} & \multicolumn{4}{|c|}{ The gap model } \\
\hline & $\begin{array}{l}\text { FE model } \\
(2 a)\end{array}$ & $\begin{array}{l}\text { MG model } \\
\text { (2b) }\end{array}$ & $\begin{array}{l}\text { CCEMG } \\
(2 \mathrm{c})^{\mathrm{A}}\end{array}$ & $\begin{array}{l}\text { CCEMG-2SLS } \\
(1 \mathrm{c})^{\mathrm{A}, \mathrm{B}}\end{array}$ \\
\hline Constant & $\begin{array}{r}-3.45 \mathrm{e}-11 \\
(.0004)\end{array}$ & $\begin{array}{r}-3.07 \mathrm{e}-11 \\
(2.14 \mathrm{e}-11)\end{array}$ & $\begin{array}{r}9.22 \mathrm{e}-12 \\
(2.03 \mathrm{e}-11)\end{array}$ & $\begin{array}{r}.0001 \\
(.0001)\end{array}$ \\
\hline$\Delta g d p_{i t}$ & 1 & 1 & 1 & 7 \\
\hline$g d p_{i t}-g d p_{i t}^{*}$ & $\begin{array}{r}-.2530 * * * \\
(.0166)\end{array}$ & $\begin{array}{r}-.2696 * * * \\
(.0241)\end{array}$ & $\begin{array}{r}-.1381 * * \\
(.0601)\end{array}$ & $\begin{array}{r}-.06890 \\
(.1090)\end{array}$ \\
\hline $\begin{array}{l}\text { Statistical } \\
\text { features of the } \\
\text { estimated } \\
\text { models: }\end{array}$ & & & & \\
\hline$R^{2}$ (within) & 0.5656 & 1 & 1 & \\
\hline $\mathrm{RMSE}^{\mathrm{C}}$ & .0056 & .0051 & .0025 & .0033 \\
\hline$C D$ test $^{\mathrm{D}}$ & $\begin{array}{l}28.11 \\
(.000) \\
\end{array}$ & $\begin{array}{l}21.21 \\
(.000)\end{array}$ & $\begin{array}{r}-1.49 \\
(.136) \\
\end{array}$ & $\begin{array}{r}-1.58 \\
(.115)\end{array}$ \\
\hline
\end{tabular}

Notes: The results of models (2a)-(2c) are presented. Although the models written above do not contain a constant, Stata reports the constant as the average of fixed effects. This does not affect parameter estimates. The standard errors of parameter estimates are given under the parameter estimates. $* * * / * * / *$ denote the $1 \% / 5 \% / 10 \%$

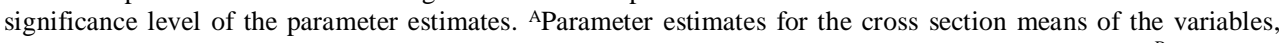
specified in models (2c), are not reported because they have no reasonable economic interpretation. ${ }^{\mathrm{B}}$ Following Neal (2015), the instrumental variable approach to 2SLS is applied. The cross-section averages, a constant and the first and second lag of the regressor and the dependent variable, are used as instruments in the CCEMG-2SLS model. For details, see Neal (2015). ${ }^{C}$ RMSE is the root mean square error. ${ }^{D} D$ test is the Pesaran's (2004) crosssection dependence test. The test statistics and the significance level for rejection of the null are noted (in parentheses). The Stata code xtcd of Eberhardt (2017) is used for the CD test.

Turning now to the estimated Okun's coefficient, the parameter estimate for the most preferred model estimates (the CCEMG-2SLS model) is statistically significant only for the difference model. This implies that Okun's validity for Slovenia can only be ascertained for the difference model when all major potential issues with panel time series models are accounted for. Going forward, therefore, the analysis is limited to the CCEMG-2SLS specification of the difference model.

The Okun's coefficient obtained from the CCEMG-2SLS specification of the difference model implies that a 1 percentage point increase (drop) in real GDP growth is associated with a 0.16 percentage point reduction (increase) in the unemployment rate. A failure to account for cross-section dependence results in an overestimated Okun's coefficient (Okun's coefficients estimated with the FE and MG estimators are -0.24), reported previously by Oberst and Oelgemöller (2013) for Germany.

Our estimates of the Okun's coefficient for Slovenia are relatively close to the estimates obtained by Banerji et al. (2015) for the adult segment of the labour market and Gabrisch and Buscher (2006) and are lower than those obtained by Malačič et al. (2009). From an international perspective, the Okun's coefficient for Slovenia is relatively low (see, e.g., Balakrishnan et al., 2010; Ball et al., 2013; 
A Regional Panel Approach to Testing the Validity of Okun'S Law: The Case of Slovenia

Banerji, 2015), which may be due to lower flexibility and greater security of employment (see, e.g., Balakrishnan et al., 2010; Ball et al., 2013). This implies that during the recovery phase of an economic cycle the local labour market may take relatively longer to recover than foreign markets.

The Okun's coefficients estimated for individual regions, based on the CCEMG-2SLS, and, for comparison reasons, also for the MG specification of the difference model are presented in Table 5. The table shows that in the case of the MG specification Okun's coefficient is statistically significant for all regions, while for the CEEMG-2SLS specification it is only statistically significant for 6 regions at the 5\% significance level. The results also demonstrate heterogeneity in Okun's coefficient: The highest significant Okun's coefficient is estimated for the Pomurska region, the lowest for the Gorenjska region. We note that some of the non-significant Okun's coefficients have an unexpected sign. Lower Okun's coefficients estimated for some regions imply that these regions' labour markets need a longer time to recover following an economic shock that led to an economic slowdown or contraction in the region. NonsignificantOkun's coefficients do not imply that there is no association between real GDP growth and the unemployment rate; they merely imply that there is no significant contemporary association. The unemployment rate in those regions may simply be more persistent (long-term).

Table 5: Okun's coefficient for individual regions in Slovenia: MG and CCEMG-2SLS specifications of the difference model

\begin{tabular}{|l|r|r|}
\hline \multirow{2}{*}{ Region } & The difference model & \\
\cline { 2 - 3 } & MG & \multicolumn{1}{|c|}{ CCEMG-2SLS } \\
\hline Pomurska & $-.3394986^{* * *}$ & $-.6901709 * * *$ \\
\hline Podravska & $-.2406536 * * *$ & .1252561 \\
\hline Koroska & $-.3154333^{* * *}$ & $-.3251496 * * *$ \\
\hline Savinjska & $-.2227472 * * *$ & .0747896 \\
\hline Zasavska & $-.3395322^{* * *}$ & -.1381494 \\
\hline Spodnjeposavska & $-.2624797 * * *$ & $-.2813235 * * *$ \\
\hline JugovzhodnaSlovenija & $-.2195601 * * *$ & .0326634 \\
\hline Osrednjeslovenska & $-.2072387 * * *$ & $-.1696911^{* *}$ \\
\hline Gorenjska & $-.1990612 * * *$ & $-.1027245^{* * *}$ \\
\hline Notranjsko-kraska & $-.2007406 * * *$ & .0570891 \\
\hline Goriska & $-.2091287 * * *$ & $-.3810061 *$ \\
\hline Obalno-kraska & $-.1611952 * * *$ & $-.1554485 * * *$ \\
\hline
\end{tabular}

Notes: The constant is not reported to save space. $* * * * * * *$ denote the $1 \% / 5 \% / 10 \%$ significance level of the parameter estimate.

The regional-level studies on Okun's coefficient claim that inter-regional heterogeneity in the sensitivity of the unemployment rate to economic cycles may be due to inter-regional differences in the level of human capital (Durech, 2014) or

DOI: 10.24818/18423264/52.3.18.03 


\section{Silvo Dajcman}

education attainment (Guisinger et al., 2015), industry structure (Durech et al., 2014; Guisinger et al., 2015), trade union membership (Guisinger, 2015), rate of labour migration and commuting (Kuscevic, 2014), or productivity growth (Villaverde and Maza, 2009). MG and all CCEMG model specifications control for some of these regional differences; by including the fixed effects in the model specification, they control for all the time-unvarying regional differences (e.g., environmental factors, time-unchanging demographic features) even though these variables are not explicitly included in the model specification. The regional differences observed from the results presented in Table 4 can then be a result of other factors not captured by the models' specifications, such as specific regional economic shocks, differential evolution of industry structures, average labour productivity growth, human capital growth, development of transport and other infrastructure important for output growth, and inter-regional labour mobility across regions and over time.

Following the reasoning of, among others, Binet and Facchini (2013), expansionary economic policy alone, especially in the regions for which Okun's law seems not to apply or the coefficient is relatively low, may not be sufficient to bring down the unemployment rate following an economic shock. Such policy should be accompanied by regional policy and measures that spur sustainable economic growth (e.g., support for regional infrastructure development, investments in research and development, education, and information and communication technology, and foreign direct investment).

\section{Conclusion}

This paper studies Okun's law in Slovenia and its NUTS 3-level regions, applying the difference and gap models for the period 2000-2015 and different panel-time series estimators: fixed effects, mean group, common correlated mean group, and common correlated mean group two-stage least squares. The results show that when all main issues identified in the panel-time series literature are accounted for (i.e., heterogeneity, cross-section dependence, and endogenous regressors), Okun's law at the national level can only be confirmed for the difference model. At the regional level, the results suggest that Okun's law applies in 6 out of 12 regions. Notable differences between regions can be observed. Factors that may explain regional heterogeneity and the relevance of the paper's findings for economic policy are discussed.

\section{REFERENCES}

[1]Apergis, Nicholas, Rezitis, Anthony (2003), An Examination of Okun's law: Evidence from Regional Areas in Greece. Applied Economics 35(10): 1147-1151; [2] Balakrishnan Ravi, Das,Mitali, Kannan, Prakash (2010), Unemployment Dynamics during Recessions and Recoveries: Okun's law and Beyond. In: 
A Regional Panel Approach to Testing the Validity of Okun'S Law: The Case of Slovenia

International Monetary Fund (Eds) World Economic Outlook 2010:Rebalancing Growth(Chapter 3, pp. 1-9). Internatonal Monetary Fund, Washington;

[3] Ball Laurence, Leigh, Daniel, Loungani, Prakash (2013),Okun's law: Fit at Fifty? NBER Working Paper No. 18668. Cambridge: NBER;

[4] Banerji Angana, Lin,H. Huidan, Saksonovs,Sergejs (2015), Youth Unemployment in Advanced Europe: Okun's Law and Beyond. IMF Working Paper No. 15/5. Washington: International Monetary Fund;

[5] Binet, Marie-Estelle, Facchini, Francois (2013),Okun's law in the French

Regions: A Cross-regional Comparison. Economics Bulletin, 33(1): 420-433;

[6] Cevik,EmrahIsmail, Dibooglu,Sel, Barişik,Salih (2014), Asymmetry in the

Unemployment-Output Relationship Over the Business Cycle: Evidence from

Transition Economies. Comparative Economic Studies 55(4): 557-581;

[7] Chudik, Alexander, Pesaran, M.Hashem (2013), Large Panel Data Models

with Cross-Sectional Dependence: A Survey. Federal Reserve Bank of Dallas

Globalization and Monetary Policy Institute Working Paper No. 153. Dallas:

Federal Reserve Bank of Dallas;

[8] Durech, R., Minea, A., Mustea, L., Slusna, L. (2014), Regional Evidence on Okun's Law in Czech Republic and Slovakia. Economic Modelling 42(C): 57-65;

[9] Eberhardt, Markus. (2012), Estimating Panel Time-series Models with

Heterogeneous Slopes. The Stata Journal 12(1): 61-71;

[10] Eberhardt, Markus. (2017), XTCD Stata routine. Available at:

https://sites.google.com/site/medevecon/code\#TOC-xtcd;

[11] Freeman,G. Donald (2000), Regional Tests of Okun's Law. International

Advances in Economic Research 6(3): 557-570;

[12] Gabrisch, Hubert, Buscher, Herbert. (2006), The Relationship between

Unemployment and Output in Post-communist Countries. Post-Communist

Economies 18(3): 261-276;

[13] Guisinger,Y. Amy, Hernández-Murillo, Ruben., Owyang,T. Michael,

Sinclair,M. Tara (2015), A State-Level Analysis of Okun's Law. Federal Reserve Bank of St. Louis Working Paper Series 2015-029A. St. Louis: Federal Reserve

Bank of St. Louis;

[14] Kuscevic, Casto Martín Montero. (2014), Okun's Law and Urban

Spillovers in US Unemployment. The Annals of Regional Science 53(2): 719-730;

[15] Lewandowski, Piotr (2007), PESCADF: Stata Module to Perform

Pesaran's CADF Panel Unit Root Test in Presence of Cross Section

Dependence. Available:

http://econpapers.repec.org/software/bocbocode/s456732.htm;

[16] Malačič,Janez, Kešeljević,Aleksandar, Sambt,Jože (2009),

Naravnastopnjabrezposelnosti $v$ Sloveniji.

RaziskavanarejenazaBankoSlovenijenaosnovirazpisa o

financiranjuraziskavzaleto 2008. Available:

https://www.bsi.si/library/includes/datoteka.asp?DatotekaId=4163;

DOI: 10.24818/18423264/52.3.18.03 
Silvo Dajcman

[17] Neal, Timothy (2015), Estimating Heterogeneous Coefficients in Panel Data Models with Endogenous Regressors and Common Factors. Workblacking Paper;

[18] Neal, Timothy (2016), XTCCE: Stata Module to Implement the Common Correlated Effects Estimator. Available:

https://ideas.repec.org/c/boc/bocode/s458094.html;

[19] Oberst, A.Christian., Oelgemöller, Jens. (2013), Economic Growth and Regional Labor Market Development in German Regions: Okun's Law in a Spatial Context. FCN Working Paper No. 5/2013. Available at SSRN: https://ssrn.com/abstract=2240260 or http://dx.doi.org/10.2139/ssrn.2240260;

[20] Okun, M. Arthur (1962), Potential GNP: Its Measurement and

Significance. American Statistical Association, Proceedings of the Business and Economics Statistics Section, pp. 98-104;

[21] Pesaran, M.Hashem (2004), General Diagnostic Tests for Cross Section Dependence in Panels. IZA Discussion Paper No. 1240. Bonn: Institute of Labor Economics;

[22] Pesaran, M.Hashem (2006), Estimation and Inference in Large

Heterogeneous Panels with a Multifactor Error Structure. Econometrica 74(4): 967-1012;

[23] Pesaran, M.Hashem (2007), A Simple Panel Unit Root Test in the Presence of Cross Section Dependence. Journal of Applied Econometrics 22(2): 265-312;

[24] Pesaran, M.Hashem., Smith, Ronald (1995), Estimating Long-run

Relationships from Dynamic Heterogeneous Panels. Journal of Econometrics 68(1): 79-113;

[25] Villaverde, José, Maza, Adolfo. (2009), The Robustness of Okun's Law in Spain, 1980-2004: Regional Evidence. Journal of Policy Modelling 31(2): 289297. 